\title{
5. MENTAL PREPARATION OF STUDENTS PRECEDING THE COURSE
}

\begin{abstract}
Alice Florentin $^{175}$
Abstract: In the preparation of"complete actors" only the technical aspects are not decisive, they will not only train them for the level of mastery. Aerobic exercises, forexample, can only play a part in recreation and muscular development, but when we talk about the scenic movement that uses actors' preparation, the situation changes; the future actor has to work out physical exercises by passing through the mental as well as the spiritual filter. Each student should think about how the exercises indicated by the teacher feel in their bodies, the reception may be different from the way the teacher / college actors / dancers experience the movement. In this context, the student is the only expert in what he likes to do with the movements indicated by the one in front of him, or what emotions are evoked when he experiences a choreographic phrase. This makes the study of acting or dance a form of art, and the difference is given by their inner experiences. the uniqueness of the body on the move."
\end{abstract}

Key words: pedagogy, acting, body expression

\section{Introduction}

The training of 'complete actors' does not only rely on technical aspects, not only they will train them for the level of skill. For instance, aerobic exercise can only play a part in recreation and muscle development, but when the movement on the scene that uses the training of actors is concerned, the situation changes; the future actor must do physical exercise passing them both the mental filter and the spiritual one. Each student must think about the way in which the exercise indicated by their professor is felt in their body, reception being different from the way in which the professor or actor/dancer colleagues experience movement. In this context, the student is the only expert in what he or she likes to do with the movements indicated by the person standing in front of him or her or the type of emotions evoked when he or she experiences a choreographic sequence. This makes the study of acting or dance a form of art, and the difference is set by their inner experiences, the uniqueness of the moving body.

\section{Discussions}

Since the actor/dancer is aware of uniqueness, the beginning of development of an artistic voice is marked through motion. The supervisor must select the strong points from experience in order to provide valuable ideas in the training of the artist. The internalization of becoming aware of the role played

\footnotetext{
${ }^{175}$ Doctoral Candidate, "George Enescu" National University of Arts from Iaşi, Romania, email: alice.ioana.florentin@gmail.com
} 
by the mind during the course of movement can lead to the development of the student as a professional interpreter; technical and mental habits developed in the class will be reflected in his or her experiences as a performer. A method of developing this mental focus consists in 'dancing with the mind', a concept known in specialised literature as 'mindfulness'.

As humans, we tend, both in life and in art, to fall into routine; like when we drive the car without being mentally involved and get home without providing too many details on the route. If we would have been stuck in a major traffic jam, the new pieces of information would have surprised us and we would focus our entire attention on some behavioural patterns that have fallen into our routine. A conscious approach of new experiences allows the brain to absorb more pieces of information and use acquired information better. The most important aspect lies in the fact that an open thinking allows changing behaviour because it drives us away from automatic response patterns.

A routine in movement/dance/body training can seriously the 'growing' and success of students. The student confronted with a familiar movement and will experience it in the same manner blocks his or her development, path towards innovation. For example, the professor offers the group exercise; the student immediately admits that it is the same or similar to the one with which he or she was confronted one day before and says: 'Well, I know this exercise. Let's get started! I know what to do!' Then, the professor must intervene and suggest the repetition of the exercise, as they did one day before, but adding the new experience, especially by involving the mind as an opportunity to achieve a new goal or to make technical progress.

It is very important for us to make the students in front of us realise that it is up to them how much they want to develop as artists. The professor is present there in order to guide them, provide them with information, inspire them and enrich their experience, but the power to recreate themselves, incite their mind and curiosity/desire to go as far as possible is theirs, as future theatrical creators.

Perhaps the most difficult task of a student, as a beginner, is the one to understand his responsibility for guiding his or her own progress. The professor is a leader, providing ideas that worth investigation - both physical and mental, but the task of the student (communicated by the professor) is the one to respond completely and artistically to the given task (on the content/information provided before); in order to fully profit by the acquired notions, the student will have to involve, besides psychic, the mind and spirit.

The professor is less worried by the fact that the student memorised a choreographic sequence precisely; he or she is rather worried by the way in which they reproduce the steps. Developed habits can be difficult to brake and, if there is a habit, a method that the student masters to perfection and refuses to quit that area of movement and creation, progress will be difficult to make. In this case, the professor will find a way to make the students pay equal attention to repeated steps - perhaps, by spicing the course every time with a challenge. 
There is great satisfaction from both parties whenever something that seems difficult, hard to achieve in the beginning, attains the objective. This method of setting long-term objectives determines the delay of satisfaction. Patience must appear in the 'equation' and they must be sought by both parties (student and professor) through the challenges and enhancing the value of strong points specific to each group of study.

Martha Graham said that it takes somebody ten years to become a dancer. This opinion is certainly a challenge, but it can be also an objective. The four essential steps to develop movement abilities are as follows: reflection (thinking), repetition, creativity and patience. We will suggest, in the following lines, an extremely strong exercise, for relieving daily stress, before the beginning of the course. The students who succeeding in calming down during the course, are more rooted in the present, more creative, happier and will succeed in gaining information provided by their professor much better! The 'performers' who enjoy the greatest visibility in the present-day artistic world perform rigorous rituals of de-stressing, before going public. We can notice them before the beginning of a show how they breathe deeply, close their eye for a moment, enter the atmosphere, flex their muscles and legs in order then to relax. All these actions help them relieve stress, ease their mind, relax their body and to give their best in the most important moment. This moment can be called self-update.

We will describe in the following lines one of the most efficient relaxation techniques, known as straining and relief. The student is challenged to think about a stressful situation, which he faced over the last month. He or she must re-enact in their mind and connect themselves to the emotion that they experienced at that time. Then, he or she must locate it somewhere in their body and feel the sensation of discomfort that the thought creates within him or her. Perhaps the sensation is located in the throat, heart, chest, solar plexus or abdomen. The student must touch that part of his or her body and assess the level of stress on a scale from 1 to 10 .

During the following stage, the student must take a deep breath, take his or her hand from 'the point of stress' and clench his right fist, going on holding their breath, increases their strain taking it from the wrist to the forearm, elbow, biceps to the shoulder. The breath is held for 10 seconds, then the arm is relaxed, expiration takes place and the hand is shaken.

\section{Results}

The exercise is then extended to the right foot, straining it for about 10 seconds from the ankle and calf to the thigh, taking a deep inspiration, while muscles are well strained. Muscles are relaxed alongside expiration. The movement is repeated with the left leg, straining it for about 10 seconds from the ankle and calf to the thigh. Both legs are then shaken. The last stage comprises the straining of both the legs and arms, holding breath, gathering the abdomen 
well, everything for about 10 seconds. The relaxation of arms, legs and abdomen then follows, accompanied by expiration. There needs a moment of rest in which blood must resume its normal circulation in the body. Then, the student will try to take a conscious breath: nasal slow and deep inspiration and expiration, accompanied by a groan during expiration. After the last 'groan', the student is asked to analyse what happens to his or her body after the exercise.

The exercise does not take long (only several minutes), but the tension induced to the body made the entire quantity of blood from the body to concentrate in those area, stimulating, at the level of chemical substances, a reaction of 'fight-or-flight' without an external threat. Because we passed the 'stressful factor' from one part to the other, from upper to lower limbs, then we strained the central part of the body, pumping blood in the abdomen, we determined the well-known physical sensation 'fight-or-flight', relating ourselves to the vegetative nervous system. We are first interested in the fact that, by relieving tension, we sent a signal to the 'body-mind', a signal that tells us that the threat is gone, diminishing the force of the reaction 'fight-or-flight' and all its consequences. The relaxation effect of this exercise is not only manifested in muscles, but in molecules.

\section{Conclusions}

The relieving of daily stress generates a good prerequisite for creativity, based on a mental setting focused on the correlation of objectives with the aesthetic vision. Mental training is under the spotlifht of many schools of theatre, represents a constant preoccupation for many creators; we will exemplify by specifying an example given by Eugenio Barba: 'A thought is force in motion, an action, an energy that changes: from one point to reach another one, following paths that suddenly change their direction. As there is a slow, predictible and flat method of movement, there is also a slow, predictible and flat method of thinking. The flow of thought can be burden and blocked by already-issued stereotypes, objections and judgements. The creative thought is distinguished by its own flowing in jumps, through a sudden bewilderment that forces it to reorganise itself, in a new form, abandoning its protective shell and perforating what appears in an inert form whenever we imagine, reflect or act ${ }^{176}$

\section{References}

1. Barba, Eugenio, Casa în flăcări; despre regie și dramaturgie, Traducere DianaCozma, Editura Nemira, București, 2012

2. Tatai Alexandru, Creativitatea actorului. Dimensiunea formative, Edidura Universității de Artă Teatrală, Târgul Mureș, 2009

3. Allain, Paul, Harvie, Jen, Ghidul Routledge de teatru și performance; Traducere Cristina Modreanu, Ilinca Tamara Todoruț, Editura Nemira, 2006

\footnotetext{
${ }^{176}$ Barba, Eugenio, Casa în flăcări; despre regie și dramaturgie, traducere Diana Cozma, Editura Nemira, București, 2012, p.173
} 